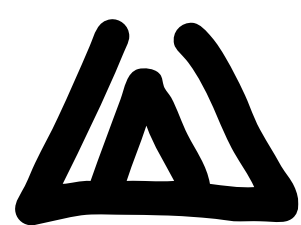

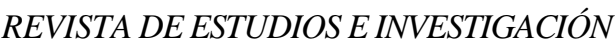

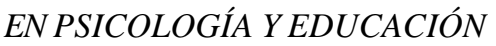 \\ ISSN: 1138-1663; eISSN: 2386-7418 \\ (c) UDC / Uminho \\ 2015, Vol. 2, No. 2, 69-79. DOI: 10.17979/reipe.2015.2.2.1328
}

\section{Searching for predictors of the risk decision-making process in social situations in the adolescence}

\author{
Búsqueda de predictores del proceso de toma de decisiones de riesgo en \\ situaciones sociales en la adolescencia
}

\author{
Iván Padrón, María Josefa Rodrigo, Manuel de Vega \\ University of La Laguna
}

\begin{abstract}
This study examined how well self-reported sensation seeking, empathy and resistance to peer influence, and performance on the computer-based measure to evaluate risk-taking behavior (Balloon Analogue Risk Task, BART) predicted the risk decision-making process on the computer-based Social Context Decision Task (SCDT). Participants were 256 early, mid- and late adolescents and young adults, distributed by age and gender. Early adolescents scored lower on sensation seeking and empathy than late adolescents and young adults. Men scored higher on sensation seeking whereas women scored higher on empathy and resistance to peer influence. Regression models showed that riskiness on the BART was positively related to the percentage of risk elections and shorter decision times in the SCDT task, with the BART parameters accounting for variance in these measures beyond that accounted for by age, gender and Disinhibition. These results contributed to a more comprehensive multimethod assessment of the process of risk decision making in social situations.
\end{abstract}

Keywords: Balloon Analogue Risk Task, risk decision-making, adolescence, social situations

\begin{abstract}
Resumen
Este estudio examina en qué medida los resultados de los cuestionarios de autoinforme sobre búsqueda de sensaciones, empatía y resistencia a los iguales, y la ejecución en una tarea de ordenador que mide el comportamiento de toma de riesgos (BART) son buenos predictores del proceso de toma de decisiones de riesgo en la tarea de Toma de Decisiones en Contextos Sociales (TDCS). Una muestra de 256 participantes distribuidos de forma equitativa por sexo y edad: adolescencia temprana, media y tardía y jóvenes adultos. Los adolescentes tempranos muestran puntuaciones más bajas en búsqueda de sensaciones y empatía que los adolescentes tardíos y los jóvenes adultos. Los hombres tienen puntuaciones más altas en búsqueda de sensaciones mientras que las mujeres puntúan más alto en empatía y resistencia a la influencia de los iguales. Los modelos de regresión muestran que el grado de riesgo en el BART está positivamente relacionado con el porcentaje de elecciones de riesgo y un tiempo de decisión más corto en la tarea TDCS, más allá de lo que explica la edad, el sexo y la desinhibición. Estos resultados contribuyen a una evaluación más comprehensiva y multi-método del proceso de toma de decisiones de riesgo en situaciones sociales.
\end{abstract}

Palabras clave: BART, toma de decisiones de riesgo, adolescencia, situaciones sociales

This work was supported by the Spanish Ministry of Economy and Competitivity under the Grant PSI 2012-32879 to María José Rodrigo, and by the NEUROCOG project supported by the Canarian Agency for Research, Innovation and the Information Society and the European Regional Development Funds to Manuel de Vega.

Iván Padrón, María Josefa Rodrigo, Manuel de Vega: Dpt. Developmental Psychology and Education, Faculty of Psychology, University of La Laguna Campus de Guajara, 38071, La Laguna, Santa Cruz de Tenerife, Spain.

Correspondence concerning this article should be addressed to Iván Padrón González. E-mail: ivpadron@ull.es 
Adolescence is a developmental period characterized by decisions and actions that give rise to risky behavior. Risky behaviors are those with high subjective desirability but great potential for harm (Byrnes, Miller, \& Schafer, 1999; Geier \& Luna, 2009). Research on risk taking has encompassed a variety of unhealthy behaviors including alcohol consumption, tobacco use, risky sexual activity, dangerous driving and dangerous sport activities (Boyer, 2006). It is broadly acknowledged that many of these types of risk-taking behaviors emerge in early adolescence, and eventually peak in mid-late adolescence (e.g., Finer \& Henshaw, 2006; Steinberg, 2008; Windle et al., 2008; Youth Risk Behavior Survey, 2013). Given the negative impact of these behaviors, there is a recognized need for investigation of the factors that increase the likelihood of health risk behavior engagement as well as the development of sound measures that allow for the evaluation of the processes underlying risk decision making across individuals. There is also a need to explore the risk decision-making process in social contexts, such as those in which the decisions are made in presence of peers. The present study is aimed at providing evidence on some of the factors that may increase the likelihood of making risk decisions in simulated social contexts. Age-sensitive constructs based on self-reports (sensation seeking, empathy and resistance to peer influences) as well as a computer-based measure to evaluate risk-taking behavior (BART task) were used as predictors of risk decision making in social situations based on a computer-based measure (SCDT task) in a sample of adolescents and young adults.

The assessment of adolescent risk taking has relied heavily on the use of self-report instruments measuring some personality traits, among others, three age-sensitivity constructs: sensation seeking, empathy and resistance to peer influence. Sensation seeking is defined by the search for experiences and feelings, that are varied, novel, complex and intense, and by the readiness to take physical and social risks for the sake of such experiences (Zuckerman, Eysenck, \& Eysenck, 1978). Developmental studies have shown that age differences in sensationseeking follow a curvilinear pattern, with sensation seeking increasing between 10 and 15 and declining or remaining stable thereafter (Steinberg, Albert, Cauffman, Banich, Graham \& Woolard, 2008). Studies on individual differences in sensation-seeking tendencies have shown that high sensation seekers are more likely to engage in risk-taking behavior than low sensation seekers (Boyer, 2006; Crone, Bullens, Van Der Plas, Kijkuit \& Zelazo, 2008; Krain et al., 2006; van Leijenhorst et al., 2008). Risk taking could also be modulated by the adolescent perspective-taking abilities when confronted with a risk scenario (Blakemore \& Coudhury, 2006). Developmental studies have demonstrated that perspective taking undergoes developmental changes until late adolescence
(Choudhury, Charman, Bird, \& Blakemore, 2007; Blakemore \& Robbins, 2012), and that these changes also occurred in simulated decision-making situations were peers are present (Rodrigo, Padrón, de Vega \& Ferstl, 2014). However, there is not much research on the impact of perspective taking on risk-taking behavior. With respect to resistance to peer pressure, there is a dramatic increase in the amount of time spent with peers during the transition from childhood to adolescence (Brown, 2004). This coincides with a greater sense of the importance of conforming to peer group norms, and a growing divergence of peer and family values as peers begin to approve of more negative behaviors (Steinberg, 2008). Resistance of peer pressure is seen as an ability that may help them to overcome this tendency. Overall, teenagers are less resistant to peer pressure than either children or adults, although susceptibility to peer influence gradually decreases over the course of adolescence (Steinberg \& Monahan, 2007). Consequently, high scores on resistance were related to less risk-taking behavior (Monahan, Steinberg, \& Cauffman, 2009).

The above constructs are developmentally sensitive and seems to overlap with risk-taking behavior but they are fraught with limitations due to their exclusive reliance on self-report measures (e.g., Ladouceur et al., 2000). The Balloon Analogue Risk Task (BART; Lejuez et al., 2002) has been developed as a behavioral measure that resembles a natural risk decision-making situation and does not suffer from the above limitation. BART is a computerized behavioral measure of risk taking propensity in which the participant is presented with a display of a small balloon and asked to pump the balloon by clicking a button on the screen. With each click, the balloon inflates a small amount and actual money is added to the participant's temporary winnings. At any point, the participant has the option to press a button, which deposits the amount in temporary winnings to the bank and ends the trial, at which point a new trial begins. However, each balloon is programmed to pop somewhere at a given point. If the participant fails to press the button before the balloon pops, all earnings for that balloon are lost and the next balloon is presented. Risktaking is defined as the average number of pumps on unpopped balloons, with higher scores indicating greater risktaking. Results with a sample (ages 18-25) indicated that riskiness on the BART was correlated with scores on measures of sensation seeking, impulsivity, and deficiencies in behavioral constraint (Lejuez et al., 2002). Also, riskiness on the BART was correlated with the selfreported occurrence of addictive, health, and safety risk behaviors. Subsequent research with adults has provided further evidence for a correlation between BART scores and substance use in community and clinical samples (Bornovalova et al., 2005; Lejuez et al., 2003; Pleskac et al., 2008). Following this work, the BART was extended to middle adolescents (ages 14-17). Studies indicated that 
riskiness on the BART was related to a variety of real world self-reported risk behaviors including substance use, gambling, delinquency behaviors, and risky sexual behavior (Aklin, Lejuez, Zvolensky, Kahler, \& Gwadz, 2005; Lejuez et al., 2005; Lejuez et al., 2007).

The social context decision-making task (SCDT) was designed for experimental purposes to evaluate the risk decision-making process in social contexts (Rodrigo et al., 2014). The task involves verbal narratives describing situations in which the participants were asked to image themselves accompanied by peers either involved in risky/safe choices (e.g., drinking a lot or staying sober) in risk situations, or neutral choices (e.g., eating a hamburger or a hotdog) in ambiguous situations. The risk scenarios that were used for the present study were based on situations selected from the Youth Risk Behavior Survey (2013). They belonged to five domains: Behaviors that contribute to unintentional injuries (e.g., jumping into the sea from a high rock), risky sporting practices (e.g., climbing without appropriate equipment), unhealthy behaviors (e.g., competing to demonstrate who can eat more burgers), and alcohol and other drug use (e.g., consuming cocaine).

The present study takes advantange of the use of different methods to examine the impact of some personality traits and risk-taking behavior on the process of risk decision-making in social contexts in a sample of early, middle and late adolescence as well as young adults. Selfreported constructs of sensation seeking, empathy and resistance to peer influence and performance in the BART task were used as predictors of the risk decision making process (percentage of risk decisions and decision time) performed in simulated social contexts in the SCDT task. To this purpose, we first provided descriptive data on the self-reported measures, and examined the experimental properties of the BART, analyzing age and gender differences. We next examined the pattern of interrelation among variables. We expected that riskiness on the SCDT would be related to riskiness on the BART and would be significantly and positively associated to the self-reported constructs of sensation seeking and negatively related to empathy and the resistance to peer influence. Finally, we examined how well the self-report measures and BART parameters would predict results on the social context decision-making task (SCDT). Specifically, we expected that riskiness on the BART would predict a higher percentage of risk elections and less decision time spent in making such elections, in addition to that predicted with age and gender and self-report measures of risk-related constructs. Notice that the SCDT task involves actual decisions performed in simulated risk scenarios. Therefore, it is expected that riskiness on the BART, which also involve actual decision-making measures, would be a better predictor of SCDT measues than the self-reported measures.

\section{Method}

\section{Participants}

A total of 256 volunteers participated in the study, belonging to four age groups: sixty-four early adolescents, EA (aged 13-14; 32 female and 32 male; $\mathrm{M}=13.5, \mathrm{SD}=$ 0.5 ); sixty-four mid-adolescents, MA (aged 15-16; 32 female and 32 male; $M=15.6, S D=0.5$ ); sixty-four late adolescents, LA (aged 17-18 years; 32 female and 32 male; $\mathrm{M}=17.50$ years, $\mathrm{SD}=.50$ ) from public high schools and thirty young adults, YA (aged 19-20; 32 female and 32 male; mean age $=19.5, \mathrm{SD}=0.5$ ) from university and technical schools. School permission and written parental consent were obtained for children and adolescents prior to the assessment session. The procedure was approved by the Committee for Research Ethics and Animal Welfare at the University of La Laguna.

\section{Instruments and tasks}

Sensation Seeking Scale (Zuckerman et al., 1978; Spanish version Perez \& Torrubia, 1986) a 40-item questionnaire, each of the items contains two choices, A and $\mathrm{B}$, corresponding to a high or low versión of the same situation. Participants should indicate which of the choices most describes their likes or the way they feel. Choices referred to situations focusing on thrill and adventure seeking (TAS, desire for outdoor activities involving unusual sensations and risks, such as skydiving, scuba diving, and flying); disinhibition (DIS, Preference of "out of control" activities such as wild parties, drinking and sexual variety); boredom susceptibility (BS, intolerance of repetition or boring people, and restlessness in such conditions); and experience seeking (ES, Referring to new sensory or mental experiences through unconventional choices). Zuckerman, Eysenck y Eysenck (1978) have provided data supporting the internal consistency of the measure, with alpha coefficients ranging from .83 to .86 . The alpha coefficient for the current sample was .70. Testretest reliability over a 3 -week period also has been established $(r=.92)$.

Interpersonal Reactivity Index (IRI; Davis, 1980; Spanish adaptation: Pérez-Albéniz, De Paúl, Etxeberría, Montes \& Torres, 2003). It is a 28-item self-report questionnaire that measures cognitive (perspective taking and fantasy scales) and affective (emphatic concern and personal distress scales) aspects of empathy. Participants respond to each item using a 5-point Likert-type scale ranging from 0 (does not describe me well) to 4 (does describe me well). The perspective-taking scale assesses the tendency to spontaneously adopt the psychological point of view of others. The fantasy scale measures the respondents' tendency to identify with fictional characters, such as characters in books, movies, or plays. The empathic concern scale taps the respondents' feelings of warmth, compassion, and concern for others. The personal distress 
scale assesses self-oriented feelings of anxiety and discomfort resulting from tense interpersonal settings. Individual scores were calculated for each subscale. The alpha coefficient for the current sample was .72.

Resistance to Peer Influence (RPI) (Steinberg, L. \& Monahan, K. 2007; ad hoc translation for this study). This questionnaire presents respondents with a series of 10 pairs of statements and asks them to choose the statement that is the best descriptor (sample item: "Some people go along with friends just to keep their friends happy" BUT "Other people refuse to go along with what their friends want to do, even though they know it will make their friends unhappy"). After indicating the best descriptor, the respondent is then asked whether the description is "Really True" or Sort of True". Responses are coded on a 4-point scale, for the left descriptor: "really true" (1) and "sort of true" (2); and for the right descriptor: "sort of true" (3) and "really true" (4), and averaged. Higher scores indicate greater resistance to peer influence. The scale's internal consistency indicate that the measure demonstrates adequate and comparable reliability (Cronbach's alpha.76). The alpha coefficient for the current sample was .76.

The Balloon Analogue Risk Task (BART), (Lejuez et al., 2002) available at http://pebl.sourceforge.net/battery.html, which is a free software webpage including a battery of computerized tasks that could be used without the author's permission. The task was adapted for the Spanish version with instructions and display in Spanish. The computer screen showed a small simulated balloon accompanied by a balloon pump, a reset button labeled Collect $\$ \$ \$$, a permanent money-earned display labeled Total Earned, and a second display listing the money earned on the last balloon and labeled Last Balloon. With each pump, 5 cents were accrued in a temporary reserve (the amount of money in this reserve is never indicated to the participant). When a balloon was pumped past its individual explosion point, a "pop" sound effect was generated from the computer. When a balloon exploded, all money in the temporary bank was lost, and the next uninflated balloon appeared on the screen. At any point during each balloon trial, the participant could stop pumping the balloon and click the Collect $\$ \$ \$$ button.

After each balloon explosion or money collection, the participant's exposure to that balloon ended, and a new balloon appeared until a total of 90 balloons (i.e., trials) had been completed. These 90 trials comprised 3 different balloon types (i.e., blue, yellow, and orange). Each balloon color had a different probability of exploding. Thus, the probability that a blue balloon would explode on the first pump was $1 / 128$, average break point would be 64 pumps. If the balloon did not explode after the first pump, the probability that the balloon would explode was $1 / 127$ on the second pump, $1 / 126$ on the third pump, and so on up until the 128th pump, at which the probability of an explosion was $1 / 1$ (i.e., $100 \%$ ). The probability that a yellow balloon would explode on the first pump was $1 / 32$, average break point would be 16 pumps. The probability that an orange balloon would explode on the first pump was $1 / 8$, average break point would be 4 pumps. Participants were given no detailed information about the probability of an explosion, and they were not informed that different balloon colors had different probabilities of exploding. They were told that at some point each balloon would explode and that this explosion could occur as early as the first pump all the way up to the point at which the balloon had expanded to fill the entire computer screen (see instructions below).

The social context decision-making task (SCDT): Rodrigo, Padrón, de Vega \& Ferstl (2014). The social context decision-making task SCDT is a computerized task aimed at measuring actual decisions made in real-like situations. The stimulus presentation was controlled by means of a custom-developed script, developed in MatLab, using the Cogent 2000 v1.29 Software Toolbox (http://www.vislab.ucl.ac.uk/cogent.php/ provided in the public domain by the Laboratory of Neurobiology, University College London, UK). The task involved the presentation of short verbal narratives describing 40 risk situations in which the participants were asked to image themselves either involved in risky/safe choices (e.g., drinking a lot or staying sober) and 40 ambiguous situations involving neutral choices (e.g., eating a hamburger or a hotdog).

Example of a risk situation:

"You are in a disco with your close friend. In the toilet you and your friend meet a guy who offers you cocaine".

- Decision: 1) "You buy it" (risky choice), 2) "you tell him that you are not interested" (safe choice).

- Consequences (risky choice): 1) Negative: "You got very sick and had to go to the hospital", or 2) Positive: "you had a big "high" and felt great"

- Consequences (safe choice): Positive: "You enjoyed dancing with your friends"

We performed two normative studies involving a total of 200 participants (adolescents and young adults) for the elaboration of the verbal materials (Rodrigo et al., 2014). Both the risk and the neutral version involved a sequence of events presented on the screen as illustrated in Figure 1: 1) A second-person scenario describing "you" as accompanied by a close friend; 2) The two alternative options for the decision-making task in that scenario (risk and safe election and neutral elections); 3) The consequence of the choice selected, either positive or negative; 4) The emotional rating scale, where participants had to indicate "how do you feel about what just happened?" using a linear scale from -5 (extremely bad) to +5 (extremely good), placed at the bottom of the screen. For the present study, only the data corresponding to the risk situations and to the decision phase were used. The dependent variables used were the percentage of risk elections and decision time spent in these elections. 


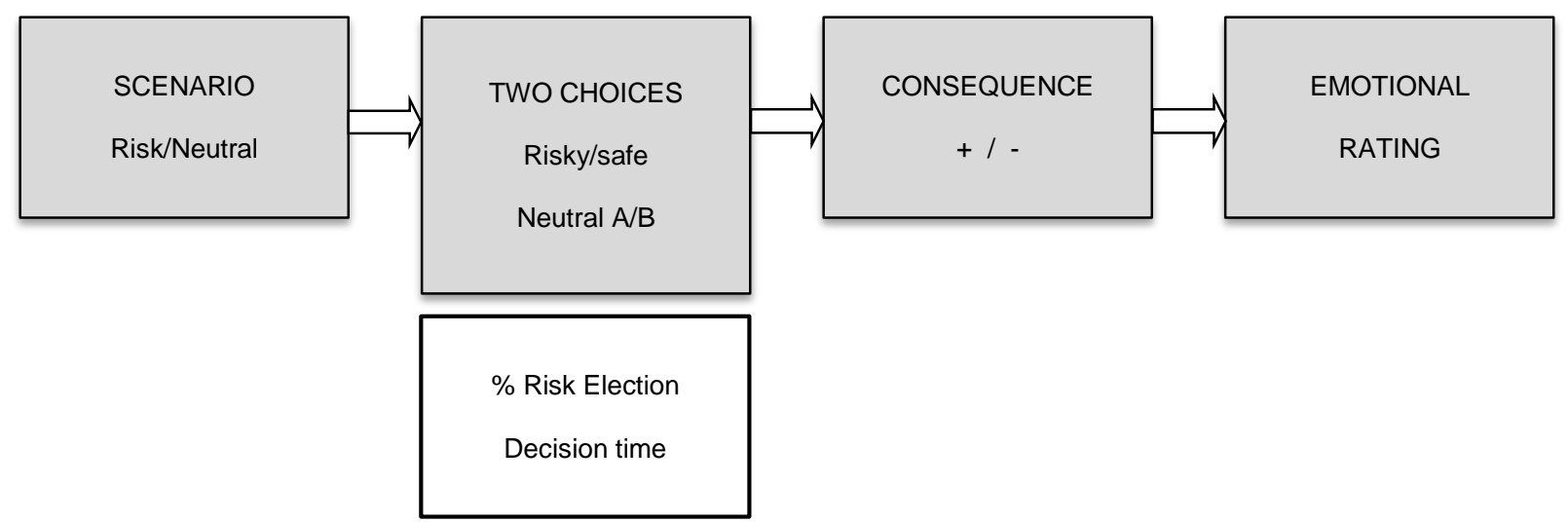

Figure 1. Trial sequences (grey boxes) and measurements recorded (white boxes).

\section{Procedure}

Once participants enter a quite room at the school half of them completed the battery of self-report assessment measures first and then, individually, the BART task and the SCDT task in another room, the other half followed a reversed order (SCDT, BART and questionnaires). The BART task was thoroughly explained with a visual depiction of the task accompanied by the following instructions, translated into Spanish. "Throughout the task, you will be presented with 90 balloons, one at a time. For each balloon you can click on the button labeled "Press This Button to Pump Up the Balloon" to increase the size of the balloon. You will accumulate 5 cents in a temporary bank for each pump. You will not be shown the amount you have accumulated in your temporary bank. At any point, you can stop pumping up the balloon and click on the button labeled "Collect $\$ \$ \$$ ". Clicking this button will start you on the next balloon and will transfer the accumulated money from your temporary bank to your permanent bank labeled "Total Earned". The amount you earned on the previous balloon is shown in the box labeled "Last Balloon". It is your choice to determine how much to pump up the balloon, but be aware that at some point the balloon will explode. The explosion point varies across balloons, ranging from the first pump to enough pumps to make the balloon fill the entire computer screen. If the balloon explodes before you click on "Collect $\$ \$ \$$ " then you move on to the next balloon and all money in your temporary bank is lost. Exploded balloons do not affect the money accumulated in your permanent bank". The duration of the BART task varied between 20 and 25 min, depending on participants' response times. For the SCDT task, participants used the same computer and they were asked to imagine themselves ("imaging you") as vividly as possible in each simulated decision-making situation accompanied with a close friend and choose between the two alternative actions. They were informed that their decisions would have positive or negative consequences with more or less impact on their health status and their popularity among friends. They were also told that there was no need to remember the performance on previous trials, because the trials were not related, and that all trials were equally important. The duration of the SRCD task varied between 25 and 30 min, depending on participants' response times. Participants were informed at the end that as a bonus for their participation one of them would win a laptop computer in a random draw to be made at the end of the data collection.

\section{Results}

\section{Descriptive analyses}

Descriptive data and age comparisons on the selfreported constructs are shown in Table 1. Early adolescents scored significantly lower than late adolescents on disinhibition $(p<.05)$, whereas scores. Early adolescents scored significantly lower than late adolescents $(p<.001)$ and young adults $(p<.01)$ on experience seeking. Early adolescents scored significantly lower than young adults on perspective taking $(p<.05)$. Early adolescents scored significantly lower than late adolescents on fantasy $(p<$ $.01)$ and empathic concern $(p<.001)$. There were also gender diferences with men scoring significantly higher than women on thrill \& adventure, $F(1,253)=8.782, p<$ $.001, \eta p 2=.034$, and disinhibition, $F(1,253)=26.449, p$ $<.001, \eta p 2=.096$. By contrast, women scored significantly higher than men on perspective taking, $F(1$, $253)=5.139, p<.05, \eta p 2=.020$, fantasy, $F(1,253)=$ $8.852, p<.01, \eta p 2=.034$, empathic concern, $F(1,253)$ $=22.666, p<.001, \eta p 2=.082$, personal distress, $F(1$, 253) $=6.730, \mathrm{p}<.01, \eta p 2=.026$, and resistance to peer influence, $F(1,253)=8.064, p<.01, \eta p 2=.032$.

With regard to the experimental properties of BART, following the original procedure (Lejuez et al., 2002), only adjusted number of pumps as the index of riskiness were used for this analysis. The adjusted number of pumps was 
not significantly related to age for any of the balloon colors $(p>.10)$, as in the original study. The adjusted average number of pumps was higher for men than for women on the blue balloon, $F(1,254)=7.36, p<.01, \eta p 2=.034$, and on the orange balloon, $F(1,254)=13.13, p<.01, \eta p 2$ $=.090($ see Table 2$)$.

Table 1.

Descriptive data and age comparisons for sensation seeking, interpersonal reactivity index and resistance to peer influence.

\begin{tabular}{|c|c|c|c|c|c|c|c|c|c|c|}
\hline \multirow[t]{2}{*}{ Factors } & \multicolumn{2}{|c|}{$\begin{array}{c}\text { Early } \\
\text { adolescence }\end{array}$} & \multicolumn{2}{|c|}{ Mid-adolescence } & \multicolumn{2}{|c|}{ Late adolescence } & \multicolumn{2}{|c|}{$\begin{array}{c}\text { Young } \\
\text { adulthood }\end{array}$} & \multirow[t]{2}{*}{$\begin{array}{c}F \\
(3,254)\end{array}$} & \multirow[t]{2}{*}{$\eta p 2$} \\
\hline & $\bar{M}$ & $S D$ & $M$ & $S D$ & $M$ & $S D$ & $M$ & $S D$ & & \\
\hline Thrill \& Adventure & 6.57 & 2.43 & 6.73 & 2.87 & 6.65 & 2.21 & 6.20 & 2.73 & 0.641 & .008 \\
\hline Disinhibition & 3.66 & 2.08 & 4.85 & 2.27 & 4.93 & 2.46 & 4.2 & 2.20 & $3.811 * *$ & .043 \\
\hline Boredom susceptibility & 4.37 & 1.49 & 4.56 & 1.78 & 4.30 & 1.92 & 3.96 & 1.99 & 0.912 & .011 \\
\hline Experience seeking & 4.96 & 1.55 & 5.55 & 1.59 & 6.11 & 1.63 & 5.76 & 1.50 & $6.869 * * *$ & .077 \\
\hline Perspective taking & 3.14 & 0.57 & 3.14 & 0.70 & 3.36 & 0.63 & 3.44 & 0.55 & $3.827 * *$ & .044 \\
\hline Fantasy & 2.75 & 0.50 & 2.84 & 0.48 & 3.06 & 0.59 & 2.82 & 0.59 & $3.917 * *$ & .045 \\
\hline Empathic concern & 3.32 & 0.52 & 3.44 & 0.47 & 3.47 & 0.55 & 3.65 & 0.42 & $4.890 * *$ & .055 \\
\hline Personal distress & 2.71 & 0.66 & 2.52 & 0.62 & 2.63 & 0.69 & 2.60 & 0.56 & 1.006 & .012 \\
\hline $\begin{array}{l}\text { Resistance to peer } \\
\text { influence }\end{array}$ & 2.55 & 0.35 & 2.6 & 0.36 & 2.59 & 0.35 & 2.7 & 0.27 & 2.469 & .030 \\
\hline
\end{tabular}

$* p<.05, * * p<.01, * * * p<.001$

Table 2.

Earnings, explosions, and average number of pumps for each balloon color by gender.

\begin{tabular}{|c|c|c|c|c|c|c|c|c|c|c|c|c|}
\hline \multirow[b]{3}{*}{ Parameters } & \multirow{2}{*}{\multicolumn{2}{|c|}{ Earnings }} & & & \multicolumn{8}{|c|}{ Average adjusted pumps } \\
\hline & & & \multicolumn{2}{|c|}{ Explosions } & \multicolumn{2}{|c|}{$\overline{\text { Total }}$} & \multicolumn{2}{|c|}{ First 10} & \multicolumn{2}{|c|}{ Middle 10} & \multicolumn{2}{|c|}{ Last 10} \\
\hline & $M$ & $S D$ & $M$ & $S D$ & $M$ & $S D$ & $M$ & $S D$ & $M$ & $S D$ & $M$ & $S D$ \\
\hline \multicolumn{13}{|l|}{ Blue } \\
\hline Men & 22.41 & 11.01 & 3.87 & 3.25 & 16.53 & 9.93 & 12.66 & 10.01 & 19.31 & 13.35 & 21.50 & 12.73 \\
\hline Women & 19.35 & 10.32 & 2.95 & 2.58 & 13.83 & 8.81 & 11.36 & 9.35 & 14.74 & 10.83 & 17.86 & 10.11 \\
\hline \multicolumn{13}{|c|}{ Adjusted blue } \\
\hline Men & & & & & 19.30 & 12.22 & 13.01 & 10.33 & 20.43 & 15.27 & 24.45 & 15.82 \\
\hline Women & & & & & 15.50 & 10.06 & 11.70 & 9.94 & 15.49 & 11.90 & 19.31 & 11.67 \\
\hline \multicolumn{13}{|l|}{ Yellow } \\
\hline Men & 9.08 & 2.55 & 8.75 & 4.24 & 8.52 & 3.24 & 8.04 & 3.72 & 8.90 & 4.19 & 9.12 & 4.03 \\
\hline Women & 8.24 & 2.82 & 6.87 & 4.27 & 7.06 & 2.96 & 6.66 & 3.27 & 7.28 & 3.84 & 7.63 & 3.70 \\
\hline \multicolumn{13}{|c|}{ Adjusted yellow } \\
\hline Men & & & & & 9.41 & 3.75 & 8.37 & 3.90 & 9.50 & 4.66 & 10.36 & 4.76 \\
\hline Women & & & & & 7.76 & 3.50 & 7.14 & 3.89 & 7.79 & 4.27 & 8.37 & 4.19 \\
\hline \multicolumn{13}{|l|}{ Orange } \\
\hline Men & 2.07 & 0.75 & 17.32 & 4.64 & 3.00 & 0.68 & 3.25 & 0.91 & 2.88 & 0.99 & 2.59 & 0.96 \\
\hline Women & 2.09 & 0.72 & 15.96 & 5.22 & 2.90 & 0.78 & 3.26 & 0.98 & 2.76 & 1.04 & 2.33 & 1.01 \\
\hline \multicolumn{13}{|c|}{ Adjusted Orange } \\
\hline Men & & & & & 3.23 & 0.96 & 3.69 & 1.48 & 3.05 & 1.33 & 3.08 & 1.24 \\
\hline Women & & & & & 3.03 & 0.92 & 3.50 & 1.49 & 3.02 & 1.22 & 2.74 & 1.26 \\
\hline
\end{tabular}

Note. Blue indicates balloons with a range of 1-128 and an average explosion point of 64; Yellow indicates balloons with a range of 1-32 and explosion point of 16; Orange indicates balloons with a range of 1-8 and an average explosion point of 4; adjusted values for each balloon color include only those balloons in which an explosion did not occur.

Regarding the blue balloon, the number of pumps differed across the 3 sets of 10 trials of the blue balloon, $F(2,254=81.70, \mathrm{p}<.001, \eta p 2=.24$, of the yellow balloon, $F(2,254=16.94, \mathrm{p}<.001, \eta p 2=.10$, and of the orange balloon, $F(2,254=21.78, \mathrm{p}<.001, \eta p 2=.15$. For the blue and yellow balloons riskiness increased between the first and second set of 10 trials $(p<.01)$, between the first set and the third set $(p<.01)$, as well as from the second set to the third set $(p<.01)$. Regarding the orange balloon, there were differences between the first and second set of 10 trials $(p<.01)$, between the first set and the third set $(p<$ $.01)$, but not from the second set to the third set $(p>.05)$. 
With regard to the SCDT task, the percentage of risky options $(35.27 \%)$ did not significantly change with age or gender. With regard to decision times, there was a facilitating effect of age on decision times, $F(3,252)=$ $4.72, p<.05 ; \eta_{p}{ }^{2}=.028$ ). The early adolescent group spent more time making the decision in risk situations than made late adolescents $(\mathrm{p}<.05)$ and young adults $(p<.05)$. Men devoted more time to make a decision, $F(1,207)=7.90, p$ $<.01 ; \eta_{p_{2}}=.019$, but women devoted more time to evaluating the risky options than men, $F(1,207)=6.15, p$ $<.01, \eta_{p 2}=.030$.

Relationship of the self-reported constructs, BART parameters and real-life risk decisions

For the present analyses we introduced the Adj BART measures obtained with the three balloons. Correlations among the self-reported constructs, BART measures on the three balloons (adjusted pumps and explosions), and reallife risk decisions in the SRCD task are also shown in Table
3. BART scores were significantly correlated with some of the relevant measures of self-reported constructs (with practically the exception of empathy measures) as well as with real-life decisions, though the scope and magnitude depends on the riskiness of the blowing (balloon color). BART measures with the blue balloon exhibited positive correlations with Thrill and Adventure Seeking and negative with Resistant to Peer Influence. They were also correlated with real-life risk decisions in the SCDT task (higher \% of risk elections and shorter decision times). BART measures with the yellow balloon exhibited positive correlations with Thrill and Adventure seeking and Disinhibition, being also positively correlated with a higher $\%$ of risk elections. Finally, BART measures with the orange balloon (the riskiest one) showed positive correlations with Disinhibition and Personal Distress and negative correlations with Resistance to Peer Influence, but not with real-life decision-making measures in the SCDT.

Table 3.

Means, Standard deviations, and correlations among study variables.

\begin{tabular}{|c|c|c|c|c|c|c|c|c|c|c|c|c|c|c|c|c|}
\hline Variable & 1 & 2 & 3 & 4 & 5 & 6 & 7 & 8 & 9 & 10 & 11 & 12 & 13 & 14 & 15 & 16 \\
\hline 1. B1 Adj pumps & -- & & & & & & & & & & & & & & & \\
\hline 2. B2 Adj pumps & $.548^{* *}$ & -- & & & & & & & & & & & & & & \\
\hline 3. B3 Adj pumps & $.148^{*}$ & $.387^{* *}$ & -- & & & & & & & & & & & & & \\
\hline 4. B1 explosions & $.810^{* *}$ & $.473 * *$ & $.216^{* * *}$ & -- & & & & & & & & & & & & \\
\hline 5. B2 explosions & $.623 * *$ & $.748 * *$ & $.316^{* *}$ & $.568 * *$ & -- & & & & & & & & & & & \\
\hline 6. B3 explosions & $.396^{* *}$ & $.618^{* *}$ & $.445^{* *}$ & $.321^{* *} *$ & $.606 * *$ & -- & & & & & & & & & & \\
\hline 7. TAS (SS) & $.132 *$ & .114 & .002 & $.179 * *$ & $.159 *$ & .054 & -- & & & & & & & & & \\
\hline 8. DIS (SS) & .047 & $.171 * *$ & .027 & .025 & $.193^{* *}$ & $.126^{*}$ & $.137 *$ & -- & & & & & & & & \\
\hline 9. BS (SS) & .111 & .101 & .031 & .122 & .040 & .043 & .055 & $.344 * *$ & -- & & & & & & & \\
\hline 10. ES (SS) & .022 & .048 & .014 & .014 & .024 & .041 & $.204 * *$ & $.181 * *$ & .052 & -- & & & & & & \\
\hline 11. RPI & $-.159 *$ & -.038 & $-.131^{*}$ & $-.146^{*}$ & -.061 & -.016 & .003 & -.117 & -.118 & .091 & -- & & & & & \\
\hline 12. FA (IRI) & .044 & -.012 & -.061 & .045 & .072 & .077 & .081 & .028 & .050 & $.155^{*}$ & -.025 & -- & & & & \\
\hline 13. PT (IRI) & .042 & -.069 & .070 & .052 & .036 & -.031 & .109 & $-.141^{*}$ & $-.140^{*}$ & $.220 * *$ & $.137 *$ & $.156^{*}$ & -- & & & \\
\hline 14. EM (IRI) & .078 & .030 & .014 & .122 & .030 & .063 & -.058 & $-.201 * *$ & $-.179 * *$ & .097 & $.181^{* *}$ & $.287 * *$ & $.275^{* *}$ & -- & & \\
\hline 15. PD (IRI) & .019 & .105 & -.008 & -.012 & .036 & $.127 *$ & $-.191 * *$ & .040 & .058 & -.082 & -.054 & $.250 * *$ & -.076 & $.217 * *$ & -- & \\
\hline $\begin{array}{l}\text { 16. \% risk election } \\
\text { SCDT }\end{array}$ & $.143^{*}$ & .079 & .013 & .063 & $.126^{*}$ & .098 & .113 & $.189 * *$ & .106 & .052 & .055 & -.033 & -.068 & .025 & -.049 & -- \\
\hline $\begin{array}{l}\text { 17. Decision time } \\
\text { SCDT }\end{array}$ & -.045 & -.049 & -.011 & $-.145^{*}$ & -.086 & -.028 & .016 & .040 & -.075 & .037 & -.077 & $-.181^{* *}$ & -.073 & $-.248 * *$ & -.034 & -.093 \\
\hline
\end{tabular}

Note: Gender: $($ Men $=1$, women $=0)$; BART task: B1, B2, B3 Adjusted pumps = the average number of pumps on the blue, yellow and orange ballon, excluded ballons that exploded; B1, B2 and B3 explosions = amount of ballons exploded on the blue, yellow and orange ballon; Sensations seeking scale (SS): TAS: Thrill and adventure seeking; DIS: Disinhibition; BS: Boredom susceptibility; ES: Experience seeking; RPI: Resistance of peer influence; Interpersonal reactivity index (IRI): FA: Fantasy; PT: Perspective taking; EM: Empathic concern; PD: Personal distress; SCDT task: \% of risk election; Decision time of risk election (ms).

$* p<.05 ; * *<.01$ 
Next, hierarchical linear regression analyses were applied separately for the measures of the \% of risk elections and decision times, as predicted by age and gender, self-report measures and BART measures corresponding to the blue, yellow and orange balloons (adjusted pumps and explosions). We wanted to examine the incremental predictive validity of the BART in accounting for variance in real-life decision making beyond that accounted for by age and gender and by self-report measures of risk-related traits. In step 1, age and gender were included as they were significantly related to study measures. In step 2, we included in successive analyses each self-reported construct. In step 3, we included in sucesive analyses the BART parameters, first all together (adjusted pumps and explosions of the three ballons) and then adjusted pumps and explosions for each ballon separately. To interpret the global significance of the models, at each step we examined the statistic $F$, the values for the Adjusted $R^{2}\left(A d j R^{2}\right)$ and the change in $R^{2}\left(\Delta R^{2}\right)$, as well as the specific contribution of each variable to the total variance explained by the model through the significance and the value of the squared semi-partial correlation $\left(\mathrm{rs}^{2}\right)$. Cases of non-colinearity, normality of residuals, linearity of the relationships between variables and homocedasticity variables were monitored (Tabachnick \& Fidell, 2007). All analyses were conducted using the SPSS 18.0 statistical software assuming a confidence level of $95 \%$ for Type I error.

Table 4.

Summary of Hierarchical Linear Regression Analyses examining the incremental validity of the Balloon Analogue Risk Task (BART) predicting risk decision-making measures in the Social Context Decision Task (SCDT).

\begin{tabular}{|c|c|c|c|c|c|c|c|c|}
\hline & \multicolumn{4}{|c|}{$\%$ Risk elections } & \multicolumn{4}{|c|}{ Decision time } \\
\hline & 8 & $r s^{2}$ & $\operatorname{Adj} R^{2}$ & $\Delta R^{2}$ & $B$ & $r s^{2}$ & $\operatorname{Adj} R^{2}$ & $\Delta R^{2}$ \\
\hline Step 1 & & & .009 & .018 & & & .037 & .047 \\
\hline Age & $.128 *$ & & & & -.127 & & & \\
\hline Gender & .035 & & & & $.178^{*}$ & .032 & & \\
\hline Step 2 & & & .048 & .055 & & & .044 & .027 \\
\hline Age & $.131^{*}$ & .016 & & & $-.172 *$ & .027 & & \\
\hline Gender & -.052 & & & & $.203 * *$ & .035 & & \\
\hline TAS & .120 & & & & -.084 & & & \\
\hline DIS & $.180 *$ & .025 & & & .036 & & & \\
\hline BS & .057 & & & & -.122 & & & \\
\hline ES & -.025 & & & & .105 & & & \\
\hline Step 3 & & & .059 & .026 & & & .096 & .060 \\
\hline Age & .109 & & & & $-.183 *$ & .029 & & \\
\hline Gender & -.066 & & & & $.204 * *$ & .034 & & \\
\hline TAS & .113 & & & & -.064 & & & \\
\hline DIS & $.179 *$ & .024 & & & .023 & & & \\
\hline BS & .053 & & & & -.118 & & & \\
\hline ES & -.021 & & & & .081 & & & \\
\hline B1 Adj pumps & $.233^{*}$ & .018 & & & $.342 * *$ & .034 & & \\
\hline B1 explosions & -.174 & & & & $-.442 * * *$ & .059 & & \\
\hline
\end{tabular}

Note: TAS: Thrill and adventure seeking; DIS: Disinhibition; BS: Boredom susceptibility; ES: Experience seeking; B1 = blue balloon

$* p<.05 ; * * p<.01 ; * * * p<.001$

Regression models for the percentage of risk elections were significant only for the blue balloon (adjusted pumps and explosions) and when including in the second step the Sensation seeking scale variables, but not with the other self-reported measures. The regression model for the percentage of risk elections was not significant in step $1, p$ $>.10$; the model was significant in step $2, F(6,235)=2.99$; $p<.01$; and in step $3, F(8,235)=2.83 ; p<.01$, explaining $10 \%$ of the variance. Higher disinhibiton and higher average of B1 adjusted pumps predicted a higher percentage of risk elections. The value of the change in $R^{2}$ shows that in step 2, the disinhibition factor added $5.5 \%$ to the variance whereas at step 3, higher average of B1 Pumps added $2.6 \%$ to the variance explained. Comparatively, disinhibition was the variable that contributed most to the increase in percentage of risk elections $\left(r s^{2}=.024\right)$, wereas average of B1 pumps contributed less $\left(r s^{2}=.018\right)$.

The regression model for the decision time of the risk election were significant only for the blue balloon (adjusted pumps and explosions) and when including in the second step the sensation seeking scale variables. The model was significant in step $1, F(2,235)=5.91 ; p<.01$; step $2, F(6$, $235)=2.48 ; p<.05$; and step $3, F(8,235)=3.51 ; p<.001$, explaining $13 \%$ of the variance. Older participant, male, and higher average of B1 adjusted pumps and smaller number of B1 exploded showed larger decision times of the 
risk election. The value of the change in $R^{2}$ shows that in step 2 , the age and gender added $2.7 \%$ to the variance, whereas at step 3 , the value of the change in $R^{2}$ shows that the two parameters of the BART added $6 \%$ to the variance explained. The number of B1 exploded contributed most to the larger decision times $\left(r s^{2}=.059\right)$, whereas B1 adjusted pumps and gender contributes less $\left(r s^{2}=.034\right)$.

\section{Discussion}

In the present study, self-reported constructs of sensation seeking, empathy and resistance to peer influence and performance in the BART task were used as predictors of the risk decision-making process in simulated social contexts in the SCDT task (percentage of risk decisions and decision time). Self-reported contructs showed age-related changes for disinhibition, experience seeking, perspective taking, fantasy, and empathic concern, as expected (Sternberg et al., 2008; Steinberg \& Monahan, 2007; Blakemore \& Robbins, 2012). In all the cases, early adolescents showed lower scores than late adolescents and young adults, suggesting an increasing trend to exhibit more risky personality traits but at the same time to promote more positive traits. Gender-related differences showed that men are at a higher risk than women of engaging in risky behavior since they reported higher scores on thrill and adventure seeking and dishinbition (Romer \& Hennessy, 2007), lower empathic abilities (personal distress, perspective taking, empathic concern and fantasy) and lower resistance to peer influence (Monahan et al., 2009), as expected. Therefore, we can be confident that we have selected age- and gender-sensitive contructs.

Some of the main experimental properties of the BART were replicated in this sample with a wider range of ages than in the original study (Lejuez et al., 2002). However, in both cases there were no age significant differences. The blue and yellow balloons were the most sensitive to gender differences and to the sucessive trials of the task, showing higher riskiness for males and increasing riskiness across trials. The orange balloon was not sensitive to gender differences and less sensitive to the successive trials. It seems that the restricted range of pumps on the orange (132) balloon and the lower average explosion points (4 respectively) produced less variability across participants than the blue and yellow balloons.

Results in the SCDT showed that percentage of risk elections remained stable around 35\%, with decision times diminishing with age probably due to improvements in executive functioning that facilitated the decision-making process (Schiebener et al., 2014). There was also evidence that women are more risk-averse than men since they spent more decision time for the risky option, though they engage in risk behaviors at levels similar to men (Bohlin \& Erlandsson, 2007; Van Leijenhorst et al., 2008).

Moderated relations have been found among the study variables. Riskiness on the BART (mainly blue and yellow balloons) was significantly and positively correlated with scores on self-report measures of thrill and adventure seeking and disinhibition (Lejuez et al., 2002) and personal distress and negatively correlated to resistance to peer influence, being two novelty results of this study. Riskiness on the BART (blue and yellow balloons) was also related to decision-making measures obtained in scenarios resembling real-world situations (SCDT). BART measures with the blue balloon were correlated with higher \% of risk elections and shorter decision times in the SCDT. BART measures with the yellow balloon were also positively correlated with a higher \% of risk elections in the SCDT. Notably, both are decision-making tasks involving actual decisions but only SCDT involves decisions taking place in sensitive scenarios for the adolescents.

In addition, regression models showed that riskiness on the BART accounted for significant variance of decisionmaking measures on the SCDT beyond that accounted for by age and gender and the self-reported measures of riskrelated constructs. Models performed with the blue balloon and sensation seeking factors (disinhibition) were the ones with more predictive value, which was not the case for the models including resistance to peer influences and empathy measures. It seems that resistance to peer influences and empathy are related to self-reported occurrence of risky behaviors (Monahan, Steinberg, \& Cauffman, 2009) but not to the decision-making process itself. By contrast, sensation seeking involves a personaliy trait that is closely related to the risk decision-making process. Individual differences in disinhibition (also impulsivity) have been linked to a host of risky behavior tendencies in both adolescents and adults (Roberti, 2004; Romer, 2010; Zuckerman, 1994). In our study, disinhibition and adjusted pumps predicted an increasing perceptage of risky elections in the SCDT. Moreover, adjusted pumps and explosions uniquely predicted the decision time of the risky option, suggesting that BART is a sensitive predictor of the time spent in the decision-making process. This is a feature of the BART that was not emphasized before, since previous studies only used self-reported occurrence of risky behavior. In this line, the BART may be used in clinical settings for the evaluation of propensity to several behavior disorders, such as conduct disorder, oppositional-defiant disorder, or attention-deficit hyperactivity disorder, which are one of the robust predictors of the development of substance use disorders, all of them associated with a history of behavioral disinhibition and poor decisionmaking (Bjork \& Pardini, 2014).

Two limitations of this study should be mentioned. It is important to better calibrate the task parameters of the BART to increase the oportunities to capture more individual variability in risk decision-making. Second, the association of the BART with the risk-related constructs and real-world risk decision-making occurred only with data from the blue balloons, accounting for a modest 
percentage of variance of the SCDT. The adjusted numbers of pumps on the yellow and orange balloons were less related to the real-world risk decisions, given that the restricted range on these balloons produced limited variability across participants. This lack of findings suggests again the need for further calibration of the BART parameters (e.g., using balloons with even greater average explosion points).

Despite these limitations, results suggest that a simple task such as the BART that works as a content-free game, is related to complex age-sensitive measures based on selfreported instruments and to a complex experimental decision-making task in simulated real-world situations. Therefore, it is a useful and potentially promising tool for examining the process of risk taking in real-life situations in combination with self-reported measures. In particular, a primary contribution of the BART may lie in tapping unique aspects of the risk decision-making related to the participants' disinhibition to engage in "out of control" activities and thereby contributing to a more comprehensive multimethod assessment of the process of risk decision making in social situations.

\section{References}

Aklin, W.M., Lejuez, C.W., Zvolensky, M.J., Kahler, C.W., \& Gwadz, M. (2005). Evaluation of behavioral measures of risk taking propensity with inner city adolescents. Behavior Research and Therapy, 43, 215228. http://dx.doi.org/10.1016/j.brat.2003.12.007

Bjork, J. M., \& Pardini, D. A. (2014). Who are those "risktaking adolescents"? Individual differences in developmental neuroimaging research. Developmental cognitive neuroscience, 11, 55-64. http://dx.doi.org/

Blakemore, S. J., \& Choudhury, S. (2006). Development of the adolescent brain: implications for executive function and social cognition. Journal of child psychology and psychiatry, 47(3-4), 296-312. http://dx.doi.org/10.1111/ j.1469-7610.2006.01611.x

Blakemore, S. J., \& Robbins, T. W. (2012). Decisionmaking in the adolescent brain. Nat. Neurosci. 15, 1184-1191. http://dx.doi.org/10.1038/nn.3177

Bohlin, M. C., \& Erlandsson, S. I. (2007). Risk behavior and noise exposure among adolescents. Noise \& Health, 9, 55-63. http://dx.doi.org/10.4103/1463-1741. 36981

Bornovalova, M., Daughters, S., Hernandez, G., Richards, J., \& Lejuez, C. (2005). Differences in impulsivity and risk-taking propensity between primary users of crack cocaine and primary users of heroin in a residential substance-use program. Experimental and Clinical Psychopharmacology, 13(4), 311-318. http://dx.doi.org /10.1037/1064-1297.13.4.311

Boyer, T. (2006). The development of risk-taking: A multiperspective review. Developmental Review, 26(3), 291345. http://dx.doi.org/10.1016/j.dr.2006.05.002

Brown, B. B. (2004). Adolescents' relationships with peers.
Handbook of adolescent psychology, 2, 363-394. http://dx.doi.org/10.1002/9780471726746.ch12

Byrnes, J., Miller, D., \& Schafer, W. (1999). Gender differences in risk taking: A meta-analysis. Psychological Bulletin, 125(3), 367-383. http://dx.doi. org/10.1037/0033-2909.125.3.367

Choudhury, S., Charman, T., Bird, V., \& Blakemore, S. J. (2007). Development of action representation during adolescence. Neuropsychologia, 45(2), 255-262. http:// dx.doi.org/10.1016/j.neuropsychologia.2006.07.010

Crone, E. A., Bullens, L., Van der Plas, E. A. A., Kijkuit, E. J., \& Zelazo, P. D. (2008). Developmental changes and individual differences in risk and perspective taking in adolescence. Development and psychopathol-ogy, 20(04), 1213-1229. http://dx.doi.org/10.1017/S095 4579408000588

Davis, M.H. (1980). A multidimensional approach to individual differences in empathy. Catalog of Selected Documents in Psychology, 10, 85, 1-17. http://www. researchgate.net/profile/Mark_Davis18/publication/34 891073_Individual_differences_in_empathy_a_multi dimensional_approach_/links/0046352dee2296ea5400 0000.pdf

Finer, L.B., \& Henshaw, S.K. (2006). Disparities in rates of unintended pregnancy in the United States, 1994 and 2001. Perspectives on Sexual and Reproductive Health, 38(2), 90-96. http://dx.doi.org/10.1363/3809006

Geier, C., \& Luna, B. (2009). The maturation of incentive processing and cognitive control. Pharmacology, Biochemistry and Behavior, 93, 212-221. http://dx.doi. org/10.1016/j.pbb.2009.01.021

Krain, A.L., Wilson, A.M., Arbuckle, R., Castellanos, F.X., Milham, M.P. (2006). Distinct neural mechanisms of risk and ambiguity: a metaanalysis of decision making. Neuroimage, 32, 477-84. http://dx.doi.org/10.1016/ j.neuroimage.2006.02.047

Ladouceur, R., Bouchard, C., Rheaume, N., Jacques, C., Ferland, F., Leblond, J., \& Walker, M. (2000). Is the SOGS an accurate measure of pathological gambling among children, adolescents and adults? Journal of Gambling Studies, 16, 1-24. http://dx.doi.org/10.1023/ A:1009443516329

Lejuez, C., Aklin, W., Bornovalova, M., \& Moolchan, E. (2005). Differences in risk-taking propensity across inner-city adolescent ever- and never-smokers. Nicotine \& Tobacco Research, 7(1), 71-79. http://dx.doi.org/ 10.1080/14622200412331328484

Lejuez, C.W., Aklin, W., Daughters, S., Zvolensky, M., Kahler, C., \& Gwadz, M. (2007). Reliability and validity of the youth version of the Balloon Analogue Risk Task (BART-Y) in the assessment of risk-taking behavior among inner-city adolescents. Journal of Clinical Child \& Adolescent Psychology, 36, 106-11. http://dx.doi.org/10.1080/15374410709336573

Lejuez C.W., Aklin, W.M., Jones, H.A., Richards, J.B., Strong, D.R., Kahler, C.W., Read, J.P. (2003). The 
Balloon Analogue Risk Task (BART) differentiates smokers and nonsmokers. Experimental and Clinical Psychopharmacology, 11, 26-33. http://dx.doi.org/10. 1037/1064-1297.11.1.26

Lejuez, C.W., Read, J.P., Kahler, C.W., Richards, J.B., Ramsey, S.E., Stuart, G.L., Strong, D.R., \& Brown, R.A. (2002). Evaluation of a behavioral measure of risk taking: the Balloon Analogue Risk Task (BART). Journal of Experimental Psychology: Applied, 8, 75-84. http://dx.doi.org/10.1037/1076-898X.8.2.75

Monahan, K. C., Steinberg, L., \& Cauffman, E. (2009). Affiliation with antisocial peers, susceptibility to peer influence, and antisocial behavior during the transition to adulthood. Developmental Psychology, 45(6), 1520. http://dx.doi.org/10.1037/a0017417

Pérez-Albéniz, A., De Paúl, J., Etxeberría, J., Montes, M. P., \& Torres, E. (2003). Adaptación de interpersonal reactivity index (IRI) al español.Psicothema, 15(2), 267-272. http://www.unioviedo.es/reunido/index.php/ PST/article/viewFile/8118/7982

Perez, J., \& Torrubia, R. (1986). Fiabilidad y validez de la version española de la Escala de Búsqueda de Sensaciones (forma V). Revista Latinoamericana de Psicología, 18, 7-22. http://www.redalyc.org/pdf/805/ 80518101.pdf

Pleskac, T., Wallsten, T., Wang, P., \& Lejuez, C. (2008). Development of an automatic response mode to improve the clinical utility of sequential risk-taking tasks. Experimental and Clinical Psychopharmacology, 16(6), 555-564. http://dx.doi.org/10.1037/a0014245

Roberti, J. W. (2004). A review of behavioral and biological correlates of sensation seeking. Journal of Research in Personality, 38, 256-279. http://dx.doi.org/ 10.1016/S0092-6566(03)00067-9

Rodrigo, M. J., Padrón, I., de Vega, M. \& Ferstl, E. C. (2014). Adolescents' risky decision-making activates neural networks related to social cognition and cognitive control processes. Frontiers in Human Neuroscience. 8:60. http://dx.doi.org/10.3389/fnhum. 2014.00060

Romer, D. (2010). Adolescent risk taking, impulsivity, and brain development: Implications for prevention. Developmental Psychobiology, 52(3), 263-276. http://dx.doi.org/10.1002/dev.20442

Romer, D., \& Hennessy, M. (2007). A biosocial-affect model of adolescent sensation seeking: The role of affect evaluation and peer-group influence in adolescent drug use. Prevention Science, 8(2), 89-101. http://dx.doi.org/10.1007/s11121-007-0064-7

Schiebener, J., García-Arias, M., García-Villamisar, D., Cabanyes-Truffino, J., \& Brand, M. (2014). Developmental changes in decision making under risk: The role of executive functions and reasoning abilities in 8-to 19-year-old decision makers. Child Neuropsychology, (ahead-of-print), 1-20. http://dx.doi. org/10.1080/09297049.2014.934216

Steinberg, L., Albert, D., Cauffman, E., Banich, M., Graham, S., \& Woolard, J.L. (2008). Age differences in sensation seeking and impulsivity as indexed by behavior and self-report: Evidence for a dual-systems model. Developmental Psychology, vol. 44, 1764-78. http://dx.doi.org/10.1037/a0012955

Steinberg, L., \& Monahan, K. C. (2007). Age differences in resistance to peer influence. Developmental psychology, 43(6), 1531. http://dx.doi.org/10.1037/ 0012-1649.43.6.1531

Tabachnick, B.G. and Fidell, L.S. (2007). Using Multivariate Statistics (5th ed.). New York: Allyn and Bacon.

Van Leijenhorst, L., Westenberg, P.M. \& Crone, E.A. (2008). A developmental study of risky decisions on the cake gambling task: age and gender analyses of probability estimation and reward evaluation. Developmental Neuropsychology, 33, 179-196. http:// dx.doi.org/10.1080/87565640701884287

Windle, M., Spear, L., Fuligni, A., Angold, A., Brown, J., Pine, D., et al. (2008). Transitions into underage and problem drinking: Developmental processes and mechanisms between 10 and 15 years of age. Pediatrics, 121(Suppl4), S273-S289. http://dx.doi.org/10.1542/ peds.2007-2243c

Youth Risk Behavior Survey. (2013). Vermont Department of Health, USA. Available at: http://healthvermont.gov/ research/yrbs/2013/documents/2013_yrbs_full_report. pdf (accessed January 4, 2015).

Zuckerman, M (1994). Biological expressions and biosocial bases of sensation seeking. Cambridge univ. Press, Nueva York.

Zuckerman, M.; Eysenck, S.B.G. \& Eysenck, H.J. (1978). Sensation seeking in England and America: Crosscultural, age, and sex comparisons. Journal of Consulting and Clinical Psychology, 46, 139-149. http://dx.doi.org/10.1037/0022-006X.46.1.139

Fecha de recepción: 10 de septiembre de 2015. Fecha de aceptación: 28 de octubre de 2015. 